\title{
Condições de adaptação e venda de lentes de contato em óticas do estado de São Paulo
}

Conditions of contact lens fitting and sale by optician stores Säo Paulo state

$\begin{array}{lcccc}\text { Andrea } & \text { Cotait } & \text { Kara } & \text { José } \\ \text { Kátia } & \text { Gargiulo } & \text { da } & \text { Cunfia } \\ \text { João } & \text { Baptista } & \text { Nigro } & \text { Santiago } & \text { Malta }^{3} \\ \text { Anaa } & \text { Carolina } & \text { Marcelo } & \text { Gomes } \\ \text { Fernando } & \text { José } & \text { De } & \text { Novellit }\end{array}$

${ }^{1}$ Aluna de graduação da Faculdade de Medicina de Jundiaí.

${ }^{2}$ Alunas de graduação da Faculdade de Ciências Médicas de Santos.

${ }^{3}$ Aluno de graduação da Faculdade de Medicina de Sorocaba.

${ }^{4}$ Médico Residente da Faculdade de Medicina da Universidade de São Paulo.

Endereço para correspondência: E-mail: fernando. novelli@bol.com.br

\section{RES UMO}

Objetivo: Avaliar as condições de adaptação e venda de lentes de contato (LC) em óticas de quatro cidades do Estado de São Paulo, Brasil. Métodos: Realizou-se estudo por meio de respostas a um questionário aplicado por quatro estudantes de Medicina em óticas situadas em várias cidades do Estado de São Paulo. Foram obtidos dados sobre a necessidade da apresentação de receita médica para a compra das LC, os tipos de LC vendidas/ adaptadas, o profissional que orienta a venda e/ou adaptação, os equipamentos usados no teste de tolerância, a conduta do cliente diante de complicações quando da adaptação da LC ou durante o uso, orientação quanto a possíveis sinais e sintomas de perigo, as doenças que contraindiquem o uso e a higiene do usuário, as horas de uso e a possibilidade de pernoite. Resultados: Das 198 óticas pesquisadas, $121(61,11 \%)$ vendem LC. Não foi necessária receita médica para a compra das lentes em 112 óticas (92,56\%), sendo que nessas, a graduação era determinada pela medida dos óculos em $69(61,61 \%)$ casos e por relato verbal em $28(25,00 \%)$ casos. Quanto aos equipamentos, $102(91,07 \%)$ óticas possuíam lensômetro; 41 (36,61\%) possuíam ceratômetro e $14(12,50 \%)$, lâmpada de fenda. Lentes descartáveis hidrofílicas foram encontradas para venda/adaptação em 66 (54,55\%) óticas; lentes hidrofílicas de uso prolongado ou diário em $68(56,20 \%)$ e lentes rígidas, em 54 (44,63\%). Em 103 (85,12\%) óticas, foram feitos testes de tolerância, sendo os responsáveis pelo atendimento e pela monitorização dos testes os profissionais autodenominados contatólogos em 78 (64,46\%) dessas óticas, balconista em 20 (16,53\%), óptico em 12 (9,92\%) e oftalmologistas em $9(7,44 \%)$. Quanto às complicações na adaptação, em 66 (54,55\%) óticas, afirmou-se que elas só ocorreriam, se evidenciadas no teste de tolerância; em 35 (28,93\%), aconselhou-se tratamento com oftalmologista e em 20 (16,53\%), sugeriu-se o retorno à ótica para indicação de tratamento. Em apenas $15(13,39 \%)$, o profissional orientou quanto à possível sintomatologia de perigo e em 13 (11,61\%), preocupou-se com doenças que contra-indicassem o uso de LC. Em 105 (93,75\%) óticas, a orientação foi insuficiente em relação à higiene com as LC, às horas de uso eà possibilidade de pernoite. Conclusão: Das 198 óticas pesquisadas, $61,11 \%$ vendem lentes de contato, sendo que em $92,56 \%$ não foram solicitadas receitas médicas; $14,88 \%$ não fizeram qualquer tipo de teste de tolerância e as óticas restantes $(85,12 \%)$ fizeram testes normalmente insuficientes para detecção de alterações induzidas por LC. Não houve preocupação com contra-indicações, sinais e sintomas de perigo nem avaliação de possíveis complicações pela presença das LC e conduta em caso de sua ocorrência, além dos cuidados mínimos de higiene durante o teste de tolerância. O profissional responsável pela adaptação (autodenominado contatólogo, balconista, ótico; ou oftalmologista) não forneceu orientação adequada sobre o uso e, em muitos casos, não deu orientação em relação à higiene.

Descritores: Lentes de contato; Lentes de contato/contra-indicações; Lentes de contato de uso prolongado; Lentes de contato hidrofílicas; Córnea/patologia; Equipamentos descartáveis; Acomodação ocular; Óptica; Questionários 


\section{INTRODUÇÃO}

Os problemas oftalmológicos mais encontrados na população em geral são os vícios de refração, cuja correção pode ser feita com óculos, lentes de contato (LC) ou cirurgia refrativa ${ }^{(1)}$.

Embora a maioria das pessoas possa usar LC, existem restrições quanto à idade do paciente, à motivação, à expectativa, às condições psicológicas, ao grau de responsabilidade, além da presença de doenças oculares e sistêmicas ${ }^{(2)}$. Deve-se salientar que a LC é um corpo estranho em íntimo contato com a córnea e que precisa ser adequadamente adaptada. Seu uso deve ser controlado, pois o usuário está sempre sujeito a complicações ${ }^{(3)}$, que vão desde conjuntivites irritativas a úlceras de córnea e mesmo perda da visão ${ }^{(1)}$.

Mesmo com o crescente progresso tecnológico das cirurgias refrativas, o número de usuários de LC vêm aumentando continuamente, graças ao desenvolvimento de novos materiais e desenhos que as tornam mais seguras, confortáveis, duráveis e favoráveis à correção da maioria das ametropias $^{(1)}$. Nos EUA e no Brasil, aproximadamente 50\% dos adultos necessitam de correção ótica, sendo que nos EUA $22 \%$ usam LC ( 25 milhões de indivíduos) e no Brasil, $6 \%$ (1.670.000 de indivíduos). Essa desproporção no número de usuários evidencia que uma série de obstáculos deve ser transposta, para permitir, a uma parcela maior da população brasileira, o acesso à correção ótica através de $\mathrm{LC}^{(1-2)}$.

$\mathrm{O}$ sucesso do uso de LC requer a escolha de uma lente adequada ao olho e demanda que o paciente tenha condições de compreender e se adaptar ao uso e limitações das lentes, bem como à aderência a seu manuseio. O paciente deve ainda estar informado em relação à conservação, ao esquema de uso e à identificação da sintomatologia de perigo e ciente do pronto acesso a cuidados especializados ${ }^{(3)}$. Assim, a adaptação de LC é, portanto, um ato médico, um processo contínuo e dinâmico que exige, além de boa acuidade visual e conforto, a manutenção das condições fisiológicas do olho dentro de limites seguros ${ }^{(3)}$. Tal controle requer, por parte do especialista, amplo conhecimento oftalmológico, no sentido de selecionar, adaptar e orientar os candidatos quanto ao uso e à manutenção da LC, além de prevenir e detectar os primeiros sinais de perigo ocular ${ }^{(4)}$. Somente assim, pode-se diminuir o crescente aparecimento de complicações pelo uso de LC, aumentando a confiança dos futuros usuários e o número dos beneficiados deste tipo de correção ótica.

Sabe-se que uma parcela da população interessada no uso de LC, por falta de conhecimento ou por comodidade, procura diretamente as óticas para adquirir as lentes e adaptá-las, sem consulta prévia com oftalmologista ${ }^{(5)}$.

O presente estudo tem por objetivo avaliar as condições de adaptação e venda de lentes de contato em óticas de quatro cidades do Estado de São Paulo.

\section{MÉTODOS}

Realizou-se um estudo sobre as condições de venda e adaptação de LC em 198 óticas de quatro cidades do Estado de
São Paulo (Jundiaí, Sorocaba, Santos e São Paulo), no período de setembro a outubro de 1999.

Em Jundiaí, Sorocaba e Santos, todas as óticas foram localizadas através da lista telefônica de 1999. Em seguida, indagou-se por telefone se essas óticas trabalhavam com LC. As que trabalhavam com $L C$ receberam a visita de pesquisadores e foram, então, incluídas na pesquisa. Na cidade de São Paulo, foram selecionadas aleatoriamente e por conveniência 100 óticas do total de 1022 existentes.

As óticas selecionadas foram visitadas por um dos quatro estudantes de Medicina (autores deste trabalho), o qual se apresentou ao primeiro atendente disponível como usuário de óculos interessado em adquirir LC. O estudante submeteu-se a toda uma rotina indicada para o uso de LC e, durante esse tempo, aplicou as perguntas de um questionário (ver anexo).

Todas as óticas que informaram vender $\mathrm{LC}$ foram visitadas e foi dito ao atendente que era a primeira vez que o entrevistador as usaria e que o mesmo não possuía receita médica, mas sabia a graduação das lentes de seus óculos. Enquanto submetido a testes de tolerância, o entrevistador anotava o tempo de duração e formulava as seguintes perguntas ao responsável pelo teste: Há possíveis doenças que possam contraindicar o uso de LC? Qual é a conduta recomendada quando da adaptação ou do uso de LC? Seria, no caso, tratamento com oftalmologista, tratamento sem oftalmologista ou nenhuma conduta? Quais os cuidados a serem tomados quanto à higiene, ao tempo de uso diário e possibilidade de pernoite? $\mathrm{O}$ entrevistador, quando não era informado, fazia perguntas sobre sinais e sintomas de perigo ocular.

Considerou-se como bom o procedimento em que o técnico responsável lavava as mãos, enxaguava as LC com soro fisiológico, após a lavagem com solução limpadora e, depois de ter as lentes removidas dos olhos do usuário, guardava as mesmas em nova solução conservadora. O procedimento foi considerado ruim, quando o profissional não lavava as mãos, não enxaguava as LC com água da torneira ou não as guardava em solução limpadora. Considerou-se como péssimo o procedimento em que o responsável não lavava as mãos e enxaguava as LC com água da torneira. Ainda, foi verificado se as LC utilizadas no teste de tolerância eram descartáveis ou permanentes. Durante a realização do teste, foram observados os equipamentos constantes na ótica, como lensômetro, ceratômetro, lâmpada de fenda e auto-refrator.

\section{RESULTADOS}

Foram contatadas, por telefone, 198 óticas em 4 cidades do Estado de São Paulo. A tabela 1 mostra que, em Santos, de um total de 39 óticas consultadas, $22(56,41 \%)$ vendiam LC; em Sorocaba, de 39 óticas, 17 (43,59\%) e, em Jundiaí, de 20 óticas, $14(70,00 \%)$ as vendiam. Em São Paulo, foram pesquisadas, ao acaso, 100 óticas, das, aproximadamente, 1022 existentes na cidade, das quais $68(68,00 \%)$ vendiam LC.

Das 121 óticas que vendiam LC, 103 (85,12\%) tinham um 


\begin{tabular}{|c|c|c|c|c|c|c|c|c|c|c|c|}
\hline \multirow{3}{*}{$\begin{array}{l}\text { Questões } \\
\text { 1) Vende LC }\end{array}$} & \multirow{3}{*}{$\begin{array}{l}\text { Respostas } \\
\text { SIM } \\
\text { NÃO }\end{array}$} & \multicolumn{8}{|c|}{ Cidades } & \multirow{2}{*}{\multicolumn{2}{|c|}{ Dados gerais }} \\
\hline & & \multicolumn{2}{|c|}{ Sorocaba } & \multicolumn{2}{|c|}{ Santos } & \multicolumn{2}{|c|}{ Jundiaí } & \multicolumn{2}{|c|}{ São Paulo } & & \\
\hline & & $\begin{array}{l}17 \\
22\end{array}$ & $\begin{array}{l}43,59 \% \\
56,41 \%\end{array}$ & $\begin{array}{l}22 \\
17\end{array}$ & $\begin{array}{l}56,41 \% \\
43,59 \%\end{array}$ & $\begin{array}{r}14 \\
6\end{array}$ & $\begin{array}{l}70,00 \% \\
30,00 \%\end{array}$ & $\begin{array}{l}68 \\
32\end{array}$ & $\begin{array}{l}68,00 \% \\
32,00 \%\end{array}$ & $\begin{array}{r}121 \\
77\end{array}$ & $\begin{array}{l}61,11 \% \\
38,89 \%\end{array}$ \\
\hline $\begin{array}{l}\text { 2) Vende LC } \\
\text { sem receita }\end{array}$ & $\begin{array}{l}\text { SIM } \\
\text { NÃO }\end{array}$ & $\begin{array}{r}14 \\
3\end{array}$ & $\begin{array}{l}82,35 \% \\
17,65 \%\end{array}$ & $\begin{array}{r}21 \\
1\end{array}$ & $\begin{array}{r}95,45 \% \\
4,55 \%\end{array}$ & $\begin{array}{r}13 \\
1\end{array}$ & $\begin{array}{r}92,86 \% \\
7,14 \%\end{array}$ & $\begin{array}{r}64 \\
4\end{array}$ & $\begin{array}{r}94,12 \% \\
5,88 \%\end{array}$ & $\begin{array}{r}112 \\
9\end{array}$ & $\begin{array}{r}92,56 \% \\
7,44 \%\end{array}$ \\
\hline $\begin{array}{l}\text { 3) Sem a receita, como } \\
\text { determina-se o grau }\end{array}$ & $\begin{array}{l}\text { Óculos } \\
\text { Relato verbal } \\
\text { Exame na óptica } \\
\text { Exame com Oftalmologista }\end{array}$ & $\begin{array}{r}13 \\
1 \\
0 \\
0\end{array}$ & $\begin{array}{r}92,86 \% \\
7,14 \% \\
0,00 \% \\
0,00 \%\end{array}$ & $\begin{array}{r}10 \\
9 \\
2 \\
0\end{array}$ & $\begin{array}{r}47,62 \% \\
42,86 \% \\
9,52 \% \\
0,00 \%\end{array}$ & $\begin{array}{l}8 \\
4 \\
0 \\
1\end{array}$ & $\begin{array}{r}61,54 \% \\
30,77 \% \\
0,00 \% \\
7,69 \%\end{array}$ & $\begin{array}{r}38 \\
14 \\
4 \\
8\end{array}$ & $\begin{array}{r}59,38 \% \\
21,88 \% \\
6,25 \% \\
12,50 \%\end{array}$ & $\begin{array}{r}69 \\
28 \\
6 \\
9\end{array}$ & $\begin{array}{r}61,61 \% \\
25,00 \% \\
5,36 \% \\
8,04 \%\end{array}$ \\
\hline $\begin{array}{l}\text { 4) Tipo de LC } \\
\text { adapta/vende }\end{array}$ & $\begin{array}{l}\text { Descartável hidrofílica } \\
\text { Hidrofílica uso diário } \\
\quad \text { ou prolongado } \\
\text { Colorida } \\
\text { Rígida } \\
\text { Todas }\end{array}$ & $\begin{array}{r}16 \\
12 \\
14 \\
6 \\
6\end{array}$ & $\begin{array}{l}94,12 \% \\
70,59 \% \\
\\
82,35 \% \\
35,29 \% \\
35,29 \%\end{array}$ & $\begin{array}{l}2 \\
3 \\
14 \\
14 \\
14\end{array}$ & $\begin{array}{r}9,09 \% \\
13,64 \% \\
\\
63,64 \% \\
63,64 \% \\
63,64 \%\end{array}$ & $\begin{array}{r}14 \\
2 \\
2\end{array}$ & $\begin{array}{r}64,29 \% \\
71,43 \% \\
\\
100,00 \% \\
14,29 \% \\
14,29 \%\end{array}$ & $\begin{array}{l}35 \\
32 \\
32\end{array}$ & $\begin{array}{l}57,35 \% \\
63,24 \% \\
\\
51,47 \% \\
47,06 \% \\
47,06 \%\end{array}$ & $\begin{array}{l}66 \\
68 \\
77 \\
54 \\
54\end{array}$ & $\begin{array}{l}54,55 \% \\
56,20 \% \\
\\
63,64 \% \\
44,63 \% \\
44,63 \%\end{array}$ \\
\hline 5) Adapta LC & $\begin{array}{l}\text { SIM } \\
\text { NÃO }\end{array}$ & $\begin{array}{r}11 \\
6\end{array}$ & $\begin{array}{l}64,71 \% \\
35,29 \%\end{array}$ & $\begin{array}{r}19 \\
3\end{array}$ & $\begin{array}{l}86,36 \% \\
13,64 \%\end{array}$ & $\begin{array}{r}12 \\
2\end{array}$ & $\begin{array}{l}85,71 \% \\
14,29 \%\end{array}$ & $\begin{array}{r}61 \\
7\end{array}$ & $\begin{array}{l}89,71 \% \\
10,29 \%\end{array}$ & $\begin{array}{r}103 \\
18\end{array}$ & $\begin{array}{l}85,12 \% \\
14,88 \%\end{array}$ \\
\hline
\end{tabular}

profissional fazendo testes de tolerância e colocando as lentes nos olhos dos fregueses e $18(14,88 \%)$ as vendiam sem realizar nenhum teste. Em 112 (92,56\%) óticas, não foi necessária receita médica específica.

Os tipos de LC oferecidos nas óticas foram: $63,64 \%$ coloridas; $56,20 \%$ hidrofílicas de tempo prolongado; $54,55 \%$ hidrofílicas descartáveis e $44,63 \%$ rígidas.

$\mathrm{Na}$ ausência de receita médica, o grau da LC foi determinado através da medida dos óculos em $61,61 \%$ dos casos e por relato verbal do pesquisador em $25,00 \%$. Em duas óticas na cidade de Santos, a graduação foi realizada por ópticos mediante teste de tentativa e erro, com lentes corretivas colocadas em armação de prova. Em uma ótica em Jundiaí e em 8 óticas em São Paulo, o entrevistador foi encaminhado para exame gratuito com oftalmologista, no consultório localizado ao lado da ótica.

Conforme se pode verificar na tabela 2, a auto-apresentação mais encontrada entre os atendentes, foi a de contatólogo, perfazendo um total de $78(64,46 \%)$, com a seguinte distribuição: $72,73 \%$ em Santos, 75,00\% em São Paulo, 47,06\% em Sorocaba e $21,43 \%$ em Jundiaí. O balconista vendeu e/ou adaptou LC em 16,53\% dos estabelecimentos, sendo $42,86 \%$ em Jundiaí, 29,41\% em Sorocaba, 18,18\% em Santos e 7,35\% em São Paulo. Em uma ótica em São Paulo, o atendente apresentou-se como especialista em LC e outro, em Jundiaí, como prático em ótica.

No que se refere aos equipamentos, $102(91,07 \%)$ óticas possuíam lensômetro; 41 (36,61\%) ceratômetro e 14 (12,50\%) possuíam lâmpadas de fenda.

O teste de tolerância foi realizado em 103 (85,12\%) óticas. Esse teste consistia na colocação de LC no olho do usuário, permanecendo esta por um período de tempo pré-determinado em cada estabelecimento. $\mathrm{O}$ intuito declarado era verificar possíveis ocorrências de reações de hipersensibilidade à $\mathrm{LC}$, aos produtos usados para a desinfecção e conservação, além do conforto e satisfação do usuário. $\mathrm{O}$ teste de tolerância teve duração de até 10 minutos em 28 (29,79\%) óticas, de 10 a 30 minutos em 40 (42,55\%), de 30 a 60 minutos em 25 (26,60\%) e superior a 60 minutos em $1(1,06 \%)$.

Em relação aos cuidados com a LC no teste de tolerância, observou-se que os responsáveis pela adaptação lavaram as mãos previamente ao manuseio da LC em $89,36 \%$ dos casos, aplicaram solução de limpeza e as guardaram adequadamente em $80,85 \%$. Usou-se soro fisiológico para limpeza de LC em $82,98 \%$ das óticas e água da torneira, em 18,09\%.

Quanto a possíveis complicações na adaptação ou uso da LC, a tabela 3 demonstra que $54,55 \%$ das óticas afirmaram que estas não ocorreriam se não fossem evidenciadas no teste de tolerância; $28,93 \%$ aconselharam tratamento com oftalmologista (sendo que, em 9 casos, o oftalmologista trabalhava para a ótica, em dependências próximas) e em $16,53 \%$, os responsáveis pela adaptação indicaram tratamento sem oftalmologista.

Não houve orientação quanto a sinais e sintomas de alerta em $86,61 \%$ dos casos. Em 88,39\% das óticas, não houve preocupação quanto à presença de doenças oculares ou sistêmicas que contra-indicassem o uso de LC.

Dentre as 121 óticas que vendiam LC, $105(93,75 \%)$ deram orientação verbal e insuficiente quanto ao manuseio da LC, às horas de uso e à possibilidade de pernoite. Nenhuma citou a possibilidade de intolerância aos produtos de limpeza e nem forneceu instruções por escrito. Duas óticas em Jundiaí perguntaram sobre alergia, glaucoma e/ou diabetes.

\section{DISCUSSÃO}

O uso de LC é uma condição patológica controlável e, para seu sucesso, faz-se necessário a correta seleção do paciente. Este deve ter expectativas realistas, noções de cuidado com as LC e da necessidade de troca delas, respeito às orientações, 


\begin{tabular}{|c|c|c|c|c|c|c|c|c|c|c|c|}
\hline & & & & & \multicolumn{5}{|c|}{ Cidades } & \multirow{2}{*}{\multicolumn{2}{|c|}{ Dados Gerais }} \\
\hline Questões & Respostas & \multicolumn{2}{|c|}{ Sorocaba } & \multicolumn{2}{|c|}{ Santos } & \multicolumn{2}{|c|}{ Jundiaí } & \multicolumn{2}{|c|}{$\overline{\text { São Paulo }}$} & & \\
\hline \multirow{2}{*}{\multicolumn{2}{|c|}{ 1) Profissional que orienta a Óptico }} & 4 & $23,53 \%$ & 2 & $9,09 \%$ & 3 & $21,43 \%$ & 3 & $4,41 \%$ & 12 & $9,92 \%$ \\
\hline & Contatólogo & 8 & $47,06 \%$ & 16 & $72,73 \%$ & 3 & $21,43 \%$ & 51 & $75,00 \%$ & 78 & $64,46 \%$ \\
\hline \multirow{3}{*}{ venda e/ou adaptação LC } & Balconista & 5 & $29,41 \%$ & 4 & $18,18 \%$ & 6 & $42,86 \%$ & 5 & $7,35 \%$ & 20 & $16,53 \%$ \\
\hline & Oftalmologista & 0 & $0,00 \%$ & 0 & $0,00 \%$ & 1 & $7,14 \%$ & 8 & $11,76 \%$ & 9 & $7,44 \%$ \\
\hline & Outros & 0 & $0,00 \%$ & 0 & $0,00 \%$ & 1 & $7,14 \%$ & 1 & $1,47 \%$ & 2 & $1,65 \%$ \\
\hline \multirow{5}{*}{$\begin{array}{l}\text { 2) Quais os equipamentos } \\
\text { usados ** }\end{array}$} & Lâmpada de fenda & 1 & $7,14 \%$ & 3 & $14,29 \%$ & 0 & $0,00 \%$ & 10 & $15,63 \%$ & 14 & $12,50 \%$ \\
\hline & Lensômetro & 14 & $100.00 \%$ & 21 & $100,00 \%$ & 8 & $61,54 \%$ & 59 & $92,19 \%$ & 102 & $91,07 \%$ \\
\hline & Ceratômetro & 5 & $35,71 \%$ & 4 & $19,05 \%$ & 4 & $30,77 \%$ & 28 & $43,75 \%$ & 41 & $36,61 \%$ \\
\hline & Auto-reflator & 0 & $0,00 \%$ & 0 & $0,00 \%$ & 0 & $0,00 \%$ & 0 & $0,00 \%$ & 0 & $0,00 \%$ \\
\hline & Nenhum & 2 & $14,29 \%$ & 1 & $4,76 \%$ & 4 & $30,77 \%$ & 2 & $3,13 \%$ & 9 & $8,04 \%$ \\
\hline \multirow{3}{*}{$\begin{array}{l}\text { 3) No teste de tolerância, } \\
\text { qual o tipo LC usado ** }\end{array}$} & Descartável & 8 & $72,73 \%$ & 2 & $10,53 \%$ & 8 & $72,73 \%$ & 6 & $11,32 \%$ & 24 & $25,53 \%$ \\
\hline & Uso diário ou prolongado & 3 & $27,27 \%$ & 6 & $31,58 \%$ & 0 & $0,00 \%$ & 47 & $88,68 \%$ & 56 & $59,57 \%$ \\
\hline & $\begin{array}{l}\text { Descartável e uso diário } \\
\text { / prolongado }\end{array}$ & 0 & $0,00 \%$ & 11 & $57,89 \%$ & 3 & $27,27 \%$ & 0 & $0,00 \%$ & 14 & $14,89 \%$ \\
\hline \multirow{4}{*}{$\begin{array}{l}\text { 4) Duração do teste de } \\
\text { tolerância com LC ** }\end{array}$} & até 10 minutos & 5 & $45,45 \%$ & 5 & $26,32 \%$ & 8 & $72,73 \%$ & 10 & $18,87 \%$ & 28 & $29,79 \%$ \\
\hline & 10 a 30 minutos & 4 & $36,36 \%$ & 3 & $15,79 \%$ & 3 & $27,27 \%$ & 30 & $56,60 \%$ & 40 & $42,55 \%$ \\
\hline & 30 a 60 minutos & 1 & $9,09 \%$ & 11 & $57,89 \%$ & 0 & $0,00 \%$ & 13 & $24,53 \%$ & 25 & $26,60 \%$ \\
\hline & mais de 60 minutos & 1 & $9,09 \%$ & 0 & $0,00 \%$ & 0 & $0,00 \%$ & 0 & $0,00 \%$ & 1 & $1,06 \%$ \\
\hline \multirow{4}{*}{$\begin{array}{l}\text { 5) Condições de higiene } \\
\text { do profissional ao } \\
\text { adaptar LC ** }\end{array}$} & $\begin{array}{l}\text { Lava as mãos antes } \\
\text { da adaptação }\end{array}$ & 9 & $81,82 \%$ & 18 & $94,74 \%$ & 10 & $90,91 \%$ & 47 & $88,68 \%$ & 84 & $89,36 \%$ \\
\hline & $\begin{array}{l}\text { Limpa as LC com } \\
\text { solucão de limpeza }\end{array}$ & 7 & $63,64 \%$ & 18 & $94,74 \%$ & 3 & $27,27 \%$ & 48 & $90,57 \%$ & 76 & $80,85 \%$ \\
\hline & $\begin{array}{l}\text { LC são guardadas } \\
\text { adequadamente }\end{array}$ & 8 & $72,73 \%$ & 17 & $89,47 \%$ & 1 & $9,09 \%$ & 50 & $94,34 \%$ & 76 & $80,85 \%$ \\
\hline & Usa soro fisiológico & 4 & $36,36 \%$ & 17 & $89,47 \%$ & 10 & $90,91 \%$ & 47 & $88,68 \%$ & 78 & $82,98 \%$ \\
\hline
\end{tabular}

\begin{tabular}{|c|c|c|c|c|c|c|c|c|c|c|c|}
\hline \multirow{5}{*}{$\begin{array}{l}\text { Questões } \\
\text { 1) Conduta frente possíveis } \\
\text { complicações no uso de LC }\end{array}$} & \multirow{4}{*}{$\begin{array}{l}\text { Respostas } \\
\text { Tratamento com } \\
\text { Oftalmologista } \\
\text { Tratamento sem } \\
\text { Oftalmologista }\end{array}$} & \multicolumn{8}{|c|}{ Cidades } & \multirow{2}{*}{\multicolumn{2}{|c|}{ Dados Gerais }} \\
\hline & & \multicolumn{2}{|c|}{ Sorocaba } & \multicolumn{2}{|c|}{ Santos } & \multicolumn{2}{|c|}{ Jundiaí } & \multicolumn{2}{|c|}{ São Paulo } & & \\
\hline & & 3 & $17,65 \%$ & 12 & $54,55 \%$ & 2 & $14,29 \%$ & 18 & $26,47 \%$ & 35 & $28,93 \%$ \\
\hline & & 3 & $17,65 \%$ & 3 & $13,64 \%$ & 0 & $0,00 \%$ & 14 & $20,59 \%$ & 20 & $16,53 \%$ \\
\hline & Nenhuma conduta & 11 & $64,71 \%$ & 7 & $31,82 \%$ & 12 & $85,71 \%$ & 36 & $52,94 \%$ & 66 & $54,55 \%$ \\
\hline $\begin{array}{l}\text { 2) Profissional orienta quanto a } \\
\text { possíveis sinais e sintomas de perigo** }\end{array}$ & $\begin{array}{l}\text { SIM } \\
\text { NÃO }\end{array}$ & $\begin{array}{r}3 \\
14\end{array}$ & $\begin{array}{l}17,65 \% \\
82,35 \%\end{array}$ & $\begin{array}{r}2 \\
20\end{array}$ & $\begin{array}{r}9,09 \% \\
90,91 \%\end{array}$ & $\begin{array}{r}0 \\
13\end{array}$ & $\begin{array}{r}0,00 \% \\
100,00 \%\end{array}$ & $\begin{array}{l}10 \\
50\end{array}$ & $\begin{array}{l}16,67 \% \\
83,33 \%\end{array}$ & $\begin{array}{l}15 \\
97\end{array}$ & $\begin{array}{l}13,39 \% \\
86,61 \%\end{array}$ \\
\hline $\begin{array}{l}\text { 3) Profissional orienta quanto a doenças } \\
\text { que contra-indiquem o uso de LC** }\end{array}$ & $\begin{array}{l}\text { SIM } \\
\text { NÃO }\end{array}$ & $\begin{array}{r}5 \\
12\end{array}$ & $\begin{array}{l}29,41 \% \\
70,59 \%\end{array}$ & $\begin{array}{r}6 \\
16\end{array}$ & $\begin{array}{l}27,27 \% \\
72,73 \%\end{array}$ & $\begin{array}{r}1 \\
12\end{array}$ & $\begin{array}{r}7,69 \% \\
92,31 \%\end{array}$ & $\begin{array}{r}1 \\
59\end{array}$ & $\begin{array}{r}1,67 \% \\
98,33 \%\end{array}$ & $\begin{array}{l}13 \\
99\end{array}$ & $\begin{array}{l}11,61 \% \\
88,39 \%\end{array}$ \\
\hline $\begin{array}{l}\text { 4) Há orientação em relação à higiene, } \\
\text { horas de uso e possibilidade de per noite }\end{array}$ & $\begin{array}{l}\text { SIM } \\
\text { NÃO }\end{array}$ & $\begin{array}{r}17 \\
0\end{array}$ & $\begin{array}{r}100,00 \% \\
0,00 \%\end{array}$ & $\begin{array}{r}19 \\
3\end{array}$ & $\begin{array}{l}86,36 \% \\
13,64 \%\end{array}$ & $\begin{array}{r}13 \\
0\end{array}$ & $\begin{array}{r}100,00 \% \\
0,00 \%\end{array}$ & $\begin{array}{r}56 \\
4\end{array}$ & $\begin{array}{r}93,33 \% \\
6,67 \%\end{array}$ & $\begin{array}{r}105 \\
7\end{array}$ & $\begin{array}{r}93,75 \% \\
6,25 \%\end{array}$ \\
\hline
\end{tabular}

facilidade de acesso ao oftalmologista para dirimir dúvidas e atendimento quando preciso. É importante, ainda, que os usuários recebam orientação sobre todos os procedimentos $\mathrm{e}$ ocorrências quanto ao uso de LC.

Os oftalmologistas realizam cursos durante sua formação médica, de modo a tornarem-se aptos à adaptação de LC. A avaliação da resposta corneana à LC exige o trabalho de profissional com conhecimentos médicos gerais e oftalmológicos específicos. Sabe-se que algumas óticas adaptam LC e, recentemente em Curitiba, Maia e col. (1999) relataram que, nessa cidade, $5,80 \%$ das 85 óticas, vendiam e/ou adaptavam LC $^{(5)}$. No Estado de São Paulo, esta situação é muito diferente, onde, de 198 óticas pesquisadas, 121 (61,11\%) vendiam LC. Essa alta porcentagem manteve-se em todas as cidades numa proporção de: 70,00\% em Jundiaí; $68,00 \%$ em São Paulo; $56,41 \%$ em Santos; e 43,59\% em Sorocaba. Verifica-se, portanto, uma freqüência maior que em Curitiba.

Observou-se que $64,46 \%$ dos profissionais que orientam a venda ou adaptação da LC se apresentaram como contatólogos, um deles como especialista em LC e outro como prático em ótica. 
Foi realizado teste de tolerância em 103 (85,12\%) óticas, enquanto $18(14,88 \%)$ vendiam LC sem qualquer teste, baseando-se apenas na hipotética graduação dos óculos ou no relato verbal do pesquisador. $O$ teste de tolerância, teve uma duração de até 10 minutos em $29,79 \%$ dos casos; de 10 a 30 minutos em $42,55 \%$; de 30 a 60 minutos em $26,60 \%$ e maior que 60 minutos em 1,06\%. Na rotina de exame oftalmológico, o paciente usa lentes de teste durante 20 a 45 minutos. Após esse período, o oftalmologista, com o auxílio de uma lâmpada de fenda, avalia a LC quanto a sua posição, mobilidade e relação física com a córnea, além da presença de lesões corneanas. Observa-se ainda, o conforto e a acuidade visual do paciente $^{(6-7)}$. Das 121 óticas, $56,20 \%$ trabalhavam com LC hidrofílica de uso prolongado ou diário, $54,55 \%$ com hidrofílica descartável e 44,63\% com a rígida. Os vendedores deram preferência às LC hidrofílicas, alegando maior tolerabilidade e possibilidade de adaptação em relação às rígidas. Ressalta-se que não foram utilizados, nos candidatos ao uso de LC, critérios de inclusão e exclusão baseados nas condições físicas, econômicas e psicológicas necessárias para possibilitar o uso correto de LC.

No processo de adaptação de LC, o oftalmologista, após examinar o paciente e selecionar as LC a serem usadas, orienta um ou mais testes, durante os quais são controladas a posição e mobilidade das lentes; observa, ainda, reações por parte do paciente como desconforto, sensação de corpo estranho, ardência, hiperemia, lacrimejamento, prurido e as condições do piscar $^{(8-9)}$ e, a seguir, faz exame do olho com e sem as LC, a olho nu e na lâmpada de fenda, para detecção de possíveis alterações oculares induzidas pelo uso da prótese ocular ${ }^{(10)}$. No entanto, estes cuidados não foram seguidos pelas óticas avaliadas.

Nenhum dos candidatos ao uso de LC foi dispensado e muitas informações importantes não foram transmitidas ao futuro usuário (complicações e contra-indicações) e nem sequer foram realizados exames básicos de tolerância. Somente em $11,61 \%$ das óticas, o profissional preocupou-se com a presença de doenças que, segundo ele, poderiam contraindicar o uso de LC. Das 198 óticas avaliadas, 9 (7,44\%) trabalhavam com oftalmologista associado.

Das 121 óticas que vendiam LC, 112 (92,56\%) não requisitaram receita médica. Assim, excetuando-se as óticas em que o oftalmologista era responsável pela adaptação das LC, todas as demais dispensaram o exame oftalmológico prévio e utilizaram, como fonte de graduação, o relato verbal ou a medida da graduação dos óculos em lensômetro.

Exame com ceratômetro foi realizado em $36,61 \%$ das óticas e com lâmpada de fenda, em 12,50\%. Apesar de algumas óticas terem alguma aparelhagem para a realização do exame ocular prévio, estas não possuíam profissionais habilitados para a realização de tais exames ${ }^{(11)}$. Essas constatações mostram que a decisão de vender LC baseou-se quase que exclusivamente na tolerância à presença da prótese no olho, além das condições de pagamento e vontade do futuro usuário.
Em relação aos cuidados com a LC no teste de tolerância, observou-se que os responsáveis pela adaptação lavavam as mãos previamente ao manuseio da LC em $89,36 \%$ dos casos; limpavam as LC com solução de limpeza e as guardavam adequadamente em $80,85 \%$. Soro fisiológico para o enxágüe foi usado em $82,98 \%$ das óticas.

Quanto às possíveis complicações na adaptação durante o uso, em $54,55 \%$ das óticas, os atendentes não instruíram os fregueses quanto à conduta a ser tomada, alegando que, caso ocorresse algum tipo de problema, este seria identificado no teste de tolerância. Dos profissionais, $16,53 \%$ orientaram sobre algum tipo de tratamento sem oftalmologista, ou seja, o uso de colírios lubrificantes, a retirada da LC na presença de incômodo e retorno à ótica. Essa mesma prática foi encontrada em Curitiba ${ }^{(5)}$. Apenas 13,39\% dos profissionais forneceram alguma orientação quanto a possíveis sinais e sintomas de perigo, o que seguramente demonstra o despreparo em relação às doenças e complicações que possam ocorrer.

Para o sucesso no uso de LC, é fundamental orientar o usuário em relação à importância da limpeza, manutenção e do manuseio das LC, além de observar a capacidade do paciente em entender tais cuidados, suas expectativas e higiene pessoal $^{(12)}$. E, ainda, enfatizar os sinais e sintomas de anormalidades, visitas de controle e os meios de comunicação com o médico em casos de dúvida. Essa última parte, por sua importância, merece cerca de $30 \%$ do tempo da adaptação inicial ${ }^{(8)}$. Essa orientação verbal e prática deve ser complementada com o fornecimento de material instrutivo escrito ${ }^{(11)}$. Um paciente sem essa orientação não estará consciente dos cuidados com a LC, seu uso e nem com a necessidade de procurar atendimento médico, em caso de dúvida ou complicação.

É conveniente estabelecer um programa de cuidados pósadaptação, com visitas médicas de acompanhamento. $O$ tempo de uso sofre influências das variações individuais, que somente poderão ser determinadas após algum tempo, quando, então, modificações na LC poderão vir a ser necessárias, em sua manutenção e na diminuição ou aumento das horas de uso. Ressalta-se que as complicações ocorridas nas primeiras horas ou nos primeiros dias tendem a ser raras e de pouca gravidade. As complicações mais graves aparecem mais comumente após meses ou anos, quando o usuário já estiver se sentindo seguro e devidamente adaptado, negligenciando o valor dos sinais de perigo, cuidados e controle médico periódico ${ }^{(7)}$. Apesar disso, em todas as óticas pesquisadas, foi realizado apenas um teste de tolerância, sem análise de possíveis alterações oculares pelo uso de LC.

As LC representam uma excelente opção para a correção de vícios de refração, quer por não alterarem a fisionomia do usuário, quer por serem, em muitos casos, a única opção de melhora das condições visuais. A evolução das LC permitiu a correção ótica de quase todas as ametropias e proporcionou maior conforto e segurança, levando a um contínuo aumento do número de usuários. Por outro lado, fatores como a facilidade de adaptação inicial e venda das lentes sem o devido 


\begin{tabular}{|c|c|c|}
\hline \multicolumn{3}{|c|}{ Anexo: Questionário } \\
\hline 1. Vende LC? & $\cdot$ SIM & • NÃO \\
\hline 2. Vende LC sem receita? & $\cdot$ SIM & • NÃO \\
\hline $\begin{array}{l}\text { 3. Sem a receita, como se } \\
\text { determina o grau? }\end{array}$ & \multicolumn{2}{|c|}{$\begin{array}{l}\text { - Óculos } \\
\text { - Relato verbal } \\
\text { - Exame na óptica } \\
\text { - Exame com oftalmologista }\end{array}$} \\
\hline $\begin{array}{l}\text { 4. Quais os tipos de LC que } \\
\text { são adaptadas ou vendidas? }\end{array}$ & \multicolumn{2}{|c|}{$\begin{array}{l}\text { - Descartável hidrofílica } \\
\text { - Hidrofílica uso prolongado } \\
\text { ou diário } \\
\text { - Coloridas } \\
\text { - Rígidas } \\
\text { - Todas }\end{array}$} \\
\hline 5. Adapta LC? & $\cdot$ SIM & • NÃO \\
\hline $\begin{array}{l}\text { 6. Qual o profissional que vende } \\
\text { e/ou adapta LC? (realiza teste de } \\
\text { tolerância com a LC) }\end{array}$ & \multicolumn{2}{|c|}{$\begin{array}{l}\text { - Óptico } \\
\text { - Contatólogo } \\
\text { - Balconista } \\
\text { - Oftalmologista }\end{array}$} \\
\hline $\begin{array}{l}\text { 7. Quais os equipamentos } \\
\text { utilizados? }\end{array}$ & \multicolumn{2}{|c|}{$\begin{array}{l}\text { - Lâmpada de fenda } \\
\text { - Lensômetro } \\
\text { - Ceratômetro } \\
\text { - Auto-refrator } \\
\text { - Nenhum }\end{array}$} \\
\hline $\begin{array}{l}\text { 8. No teste de tolerância, qual o } \\
\text { tipo de LC usado? }\end{array}$ & \multicolumn{2}{|c|}{$\begin{array}{l}\text { - Descartável } \\
\text { - Uso diário ou prolongado } \\
\text { (rígida ou hidrofílica) } \\
\text { - Descartável e uso diário / } \\
\text { prolongado }\end{array}$} \\
\hline $\begin{array}{l}\text { 9. Qual o período de duração } \\
\text { do teste de tolerância? }\end{array}$ & \multicolumn{2}{|c|}{$\begin{array}{l}\text { - até } 10 \mathrm{~min} . \\
\cdot 10-30 \mathrm{~min} . \\
\text { - } 30-60 \mathrm{~min} . \\
\cdot>60 \mathrm{~min} .\end{array}$} \\
\hline $\begin{array}{l}\text { 10. Quais as condições de } \\
\text { higiene do profissional ao } \\
\text { adaptar LC? }\end{array}$ & \multicolumn{2}{|c|}{$\begin{array}{l}\text { - Lava as mãos } \\
\text { - Limpa as LC com solução } \\
\text { estéril } \\
\text { - Guarda LC adequadamente } \\
\text { - Usa soro fisiológico }\end{array}$} \\
\hline $\begin{array}{l}\text { 11. Qual a conduta frente a possíveis } \\
\text { complicações no uso de LC? }\end{array}$ & \multicolumn{2}{|c|}{$\begin{array}{l}\text { - Tratamento com } \\
\text { oftalmologista } \\
\text { - Tratamento sem } \\
\text { oftalmologista } \\
\text { - Nenhuma conduta }\end{array}$} \\
\hline $\begin{array}{l}\text { 12. Foi realizada orientação quanto } \\
\text { a possíveis sinais e sintomas } \\
\text { de perigo ocular? }\end{array}$ & - SIM & • NÃO \\
\hline $\begin{array}{l}\text { 13. Foi realizada orientação quanto } \\
\text { a doenças que contra-indiquem } \\
\text { o uso de LC? }\end{array}$ & - SIM & • NÃO \\
\hline $\begin{array}{l}\text { 14. Foi realizada orientação em } \\
\text { relação à higiene, às horas de } \\
\text { uso e à possibilidade de pernoite? }\end{array}$ & - SIM & • NÃO \\
\hline
\end{tabular}

controle levaram a uma falsa expectativa de segurança total, seguida de despreocupação quanto aos cuidados de seu uso, acompanhado de um grande aumento do número de complicações $^{(11)}$.

As pesquisas sociológicas têm importância no tocante ao reconhecimento das práticas e condutas da saúde ocular na população, com a finalidade de orientar medidas que melhorem ou protejam a saúde da comunidade. A conduta do paciente em relação aos cuidados com a lente, obediência ao esquema de uso, atitude na presença de sintomatologia de perigo e pronto acesso ao oftalmologista, é considerada fundamental para o sucesso do uso dessas próteses.

\section{CONCLUSÃO}

Verificou-se, nas condições desta pesquisa, que, no Estado de São Paulo, a grande maioria das óticas está vendendo LC sem a requisição de receita médica ou exame oftalmológico prévio, realizando testes de tolerância insuficientes sem critérios de inclusão e exclusão dos fregueses. Os candidatos à LC são, na maioria das vezes, supervisionados por profissionais autodenominados contatólogos, que se utilizam de aparelhos privativos de oftalmologistas, desobedecem a correta conduta de higiene com as LC e não fornecem orientação adequada, que são quesitos mínimos e necessários para o uso das próteses.

Este procedimento, realizado sem seleção, controle e orientação aos usuários de LC, os coloca em risco desnecessário.

\section{AGRADECIMENTOS}

Ao Professor Doutor Newton Kara José, pelo estímulo e pela orientação durante a realização do presente trabalho.

\section{ABS T RAC T}

Purpose: To evaluate contact lens (CL) adaptation and sales in optician stores of 4 cities in São Paulo State, Brazil. Methods: A study was performed in view of the answers to a questionnaire applied by four medical students to optician stores selling contact lenses in four cities of the state of São Paulo. The researchers evaluated the need of medical prescriptions for contact lens sales, the specialist in charge of selling and/or adapting contact lenses, the types of lenses sold/adapted, the equipment used in the contact lens tolerance test, the patient's behavior facing contact lens complications during adaptation or during its use; the information given about possible signs and symptoms of risk and the patient's hygiene, as well as the number of hours of contact lens wear and their wearing during sleep. Results: Of the 198 investigated optician stores, $121(61.11 \%)$ sell contact lenses. In $112(92.56 \%)$ of the stores, medical prescription was not required for the purchase of lenses. In these stores, the contact lens degrees were determined by measuring glass lenses in $69(61.61 \%)$ of the cases and by verbal report in $28(25.00 \%)$ cases. Concerning equipment, $102(91.07 \%)$ of the stores had lensometers, 41 (36.61\%) had keratometers and 14 (12.50\%) had slit lamp. Soft disposable contact lenses were displayed for sale/adaptation in $66(54.55 \%)$ of the stores, so were soft extended and daily use contact lenses in $68(56.20 \%)$ stores 
and hard contact lenses, in 54 (44.63\%) stores. In 103 (85.12\%) stores, tolerance test was done, and the responsible persons for seeing the patient and for monitoring were professionals who called them selves contact lens fitters in $78(64.46 \%)$ of these stores, the shop assistant in $20(16.53 \%)$, the optician in $12(9.92 \%)$ and the ophthalmologist in $9(7.44 \%)$. As to complications due to contact lens adaptation, 66 (54.55\%) stores mentioned that they would happen only if they happened on the tolerance test; in 35 (28.93\%) stores, an ophthalmologist was advised for treatment and in $20(16.53 \%)$ stores, a return was suggested for information on treatment. Only in 15 $(13.39 \%)$ stores, professionals warned about possible risk symptoms and in $13(11.61 \%)$ stores, they were concerned about diseases, which contraindicate contact lens wear. In 105 (93.75\%) of the stores, professionals did not pay full attention to contact lens hygiene, wearing hours and lens wearing during sleep. Conclusion: Of the 198 investigated stores, $61.11 \%$ sell contact lenses, and $92.56 \%$ did not require medical prescription; $14.88 \%$ did not perform any kind of tolerance test and the remaining $85.12 \%$ performed tests which are normally not sufficient to detect alterations induced by contact lenses. There was no concern about contraindications, risk signs and symptoms, evaluation of possible complications resulting from contact lens wear. Neither was there concern about the least hygiene care during the tolerance test. Professionals, who call themselves contact lens fitters, shop assistants, opticians and ophthalmologists, which were responsible for adaptation give no appropriate instructions about contact lens wear and, in many cases, none about contact lens hygiene.

Keywords: Contact lenses; Contact lenses/contraindications; Extended-wear contact lenses; Hydrophilic contact lenses;
Cornea/pathology; Disposable equipment; Accomodation, ocular; Optician stores; Questionnaires

\section{REFERENCIAS}

1. Kara-José N, Coral-Ghanem C. Lente de contato na clínica oftalmológica. Joinville, Santa Catarina; Sociedade Brasileira de Lentes de Contato e Córnea; 1995.

2. Roberts J, Roubland M. Refraction status and motility defects of persons - 72 years, United States, 1971-72. Vital Health State 1978;206:1-29.

3. Coral-Ghanem C, Kara-José N. Complicações associadas ao uso de lente de contato. In: Coral-Ghanem C, Kara-José N. Lente de contato na Clínica Oftalmológica. 2a ed. Rio de Janeiro: Cultura Médica; 1998. p. 133-6.

4. Kara-José N. Prefácio. In: Moreira SMB, Moreira H. Lente de contato. 2a ed. Rio de Janeiro: Cultura Médica, 1998.

5. Maia EM, Pietrovicz J, Maia M, Ramos ARB, Moreira Jr. CA. Adaptação e venda de lente de contato pelas Óticas de Curitiba. Rev Bras Oftalmol 1999; 58:396-400.

6. Moreira SMB, Moreira H. Lentes hidrofílicas de uso flexível. In: Moreira SMB; Moreira H. Lentes de contato. 2a ed. Rio de Janeiro: Cultura Médica; 1998. p. 173-7.

7. Kara-José N, Bechara S, Bolcatti JA. Complicações pelo uso de lente de contato. In: Pena AS. Clínica de lente de contato. Rio de Janeiro: Cultura Médica, 1989. p. 125-34.

8. Kara-José N, Salles-Oliveira R. Atuação do auxiliar de Oftalmologia na adaptação de lente de contato. In: Coral-Ghanem C, Kara-José N. Lente de contato na Clínica Oftalmológica. 2a ed. Rio de Janeiro: Cultura Médica; 1998. p. 183-8.

9. Moreira SMB, Moreira H. Controle da adaptação das lentes hidrofílicas. In: Moreira SMB, Moreira H. Lentes de contato. 2a ed. Rio de Janeiro: Cultura Médica; 1998. p. 153-4.

10. Kara-José N, Cresta FB, Hatanaka M, Klein RCA, Pereira VAR, Alves MR. Perfil dos usuários de lente de contato em profissionais da área de saúde. Rev Med (São Paulo) 1997;76:307-14

11. Minguini N, Coelho RP, Serpa JF, Kara-José N, Holzchuh N. Características do uso de óculos e de lente de contato em uma comunidade universitária. Arq Bras Oftalmol 1994;57:126-8.

12. Coral-Ghanem C, Kara-José N. Manutenção das lentes de contato. In: CoralGhanem C, Kara-José N. Lente de contato na Clínica Oftalmológica. 2a ed. Rio de Janeiro: Cultura Médica, 1998. p. 113-28.

\title{
$X X^{\text {th }}$ INTERNATIONAL CONGRESS OF OPHTHALMOLOGY
}

\author{
21 a 25 de Abril de 2002
}

Sidney - Austrália

INFORMAÇÕES: www.ophthalmology.aust.com 